\title{
Northern Hemisphere Climatology and Interannual Variability of Storm Tracks in NCEP's CFS Model
}

\author{
Timothy Paul Eichler, ${ }^{1,2}$ Francisco Alvarez, ${ }^{1,3}$ and Jon Gottschalck ${ }^{4}$ \\ ${ }^{1}$ Department of Earth and Atmospheric Sciences, Saint Louis University, 3642 Lindell Boulevard, O'Neil Hall 205, St. Louis, \\ MO 63108, USA \\ ${ }^{2}$ Department of Soil, Environmental \& Atmospheric Sciences, University of Missouri, Columbia, MO 65211, USA \\ ${ }^{3}$ The Climate Corporation, 419 Occidental Avenue S., Seattle, WA 98104, USA \\ ${ }^{4}$ NOAA/National Weather Service, National Centers for Environmental Prediction, Climate Prediction Center, \\ 5830 University Research Court, College Park, MD 20740, USA
}

Correspondence should be addressed to Timothy Paul Eichler; teichler@slu.edu

Received 13 February 2015; Revised 22 April 2015; Accepted 22 April 2015

Academic Editor: Igor I. Mokhov

Copyright (C) 2015 Timothy Paul Eichler et al. This is an open access article distributed under the Creative Commons Attribution License, which permits unrestricted use, distribution, and reproduction in any medium, provided the original work is properly cited.

\begin{abstract}
Evaluating the climatology and interannual variability of storm tracks in climate models represents an excellent way to evaluate their ability to simulate synoptic-scale phenomena. We generate storm tracks from the National Center for Environmental Prediction (NCEP) Climate Forecast System (CFS) model for the northern hemisphere (NH) and compare them to storm tracks generated from NCEP's reanalysis I data, the European Centre for Medium Range Prediction (ECMWF) ERA40 data, and CFS reanalysis data. To assess interannual variability, we analyze the impacts of El Niño, the North Atlantic Oscillation (NAO), and the Indian Ocean Dipole (IOD). We show that the CFS model is capable of simulating realistic storm tracks for frequency and intensity in the NH. The CFS storm tracks exhibit a reasonable response to El Niño and the NAO. However, it did not capture interannual variability for the IOD. Since one path by which storm tracks respond to external forcing is via Rossby waves due to anomalous heating, the CFS model may not be able to capture this effect especially since anomalous heating for the IOD is more local than El Niño. Our assessment is that the CFS model's storm track response is sensitive to the strength of external forcing.
\end{abstract}

\section{Introduction}

With climate models consistently evolving to finer temporal and spatial resolution, it has become feasible to explore their ability to simulate synoptic-scale storms. The importance of investigating storms in climate models is summed up nicely by Chang and $\mathrm{Fu}[1]$, who stated that mid-latitude storms represent a linkage to weather and the maintenance of the general circulation. Analyses of storm tracks in climate models support the idea that climate models are capable of simulating extratropical cyclones. In general, two methods are utilized to assess storm tracks: Eulerian and Lagrangian. The former method uses band-passed data for the mid or upper-level height field (e.g., $500 \mathrm{hPa}$ ) and strongest wave activity to define a storm, while the latter uses minimum sealevel pressure (MSLP) or $850 \mathrm{hPa}$ vorticity to define storms.
The earliest storm track work used the Lagrangian method without an automated procedure by examining storms on weather maps (e.g., Petterson [2], Klein [3], Reitan [4], Zishka and Smith [5]). As model data became available on a monthly to subdaily temporal scales, the Eulerian method was often utilized. For example, Lau and Nath [6] examined $500 \mathrm{hPa}$ heights and MSLP from 12 winter simulations of the GFDL model to analyze spatial and temporal variability associated with teleconnection patterns such as the Pacific North American (PNA) pattern. J. S. Frederiksen and C. S. Frederiksen $[7,8]$ used a 2-level primitive equation model for the southern hemisphere to study a variety of phenomena related to cyclogenesis, blocking, and teleconnections. Chang [9] analyzed twice-daily $300 \mathrm{hPa}$ meridional wind in the GFDL general circulation model (GCM) and found that the model produced a seasonal variation in coherence similar 
to ECMWF reanalysis data. Finally, Graff and LaCasce [10] utilized band-passed $50 \mathrm{hPa}$ filtered data from the NCAR Community Climate Model Version 3 and found good agreement with data from NCEP-NCAR reanalysis I data.

While the Eulerian method allows an excellent assessment of features of the general circulation related to storm tracks, the Lagrangian method offers a more synopticoriented view of storm tracks generated by climate models. For example, Lambert et al. [11] used a Lagrangian approach to assess storm tracks in 13 models from the Atmospheric and Modeling Intercomparison Project (AMIP). They found large-scale agreement of storm events with storms generated from ECMWF (ERA) data, although regional differences were noted (e.g., the models had difficulty simulating leemountain cyclogenesis). Bengtsson et al. [12] used $850 \mathrm{hPa}$ vorticity to compare storm tracks between the ECHAM5 coupled model and ERA40 data. Similar to Lambert et al. [11], they found excellent agreement with ERA40 data, with weaker storm track generation in the lee of the Rockies. In a follow-up study, Bengtsson et al. [13] used a high resolution version of the ECHAM5 model and found that it produced a storm track climatology similar to Bengtsson et al. [12]. However, the high resolution ECHAM5 produces higher winds and greater amounts of precipitation associated with storms than the low resolution version of the ECHAM5 used by Bengtsson et al. [12]. Greeves et al. [14] investigated storms in several models from the Hadley Centre and also found excellent agreement with ERA40. Unlike other studies, Greeves et al. [14] used models with both a semi-Lagrangian dynamical core and a Eulerian core. They found that the semiLagrangian core produced more frequent storms with better defined features than the Eulerian core.

With both the Eulerian and Lagrangian methods being frequently employed in assessing storm tracks from climate models, a question is which method is most appropriate. Raible et al. [15] compared both methods utilizing NCEPNCAR and ECMWF (ERA40) reanalysis datasets and concluded that both methods were conducive for modeling studies. However, they cautioned that trends exhibited more variability between the methods. This may help explain the large variety of solutions in assessing global warming in climate models. For example, Meehl et al. [16] stated that the general consensus is that global warming results in a decrease in mid-latitude frequency and an increase in intensity of storms. However, Geng and Sugi [17], Watterson [18], Bengtsson et al. [13], and Catto et al. [19] found a decrease rather than an increase in intensity.

While the focus of modeling studies is on climate change and comparison with reanalysis datasets, less attention has been given to assessing the interannual variability of storms in climate models. Chang et al. [20] stated that while there have been several AGCM studies comparing model with observed climatologies storm track changes due to variations in the low-frequency flow component of AGCMS have not been studied as extensively. Bengtsson et al. [12] evaluated the impacts of ENSO on storm tracks in the ECHAM5 model and found that simulated storm tracks responded to ENSO-like variability in the model, especially in the Pacific. Bengtsson et al. [12] also found that the strength of the response was greater than from their ERA40 analysis. Graff and LaCasce [10] also explored ENSO impacts by uniformly increasing sea-surface temperatures (SSTs) equatorward of $15^{\circ} \mathrm{S}$ in the NCAR Community Climate model version 3 and found an equatorward shift in storm tracks in the North Pacific, similar to Eichler and Higgins [21], Chang et al. [20], and Lu et al. [22].

For the northern hemisphere, the NAO plays a significant role in altering storm tracks. For example, Bradbury et al. [23] examined effects of the NAO on New England storm tracks and found a decrease in storm frequency in northwestern New England during the negative NAO phase, likely due to an equatorward shift in storm tracks linked to highlatitude blocking. Seager et al. [24] found that precipitation anomalies in the western and southeastern U.S. during positive ENSO/negative NAO regimes were also due to an equatorward shift in the storm track.

Finally, the IOD, which refers to SST fluctuations between the eastern and western tropical Indian Ocean [25], has been found to be linked to teleconnections. Similar to ENSO, IOD impacts may be linked to Rossby wave propagation from anomalous heating due to convection. Saji and Yamagata [26] found teleconnections in opposite phase to ENSO. Effects of the IOD in climate models were demonstrated by Annamalai et al. [27], who found a negative PNA response in the ECHAM5 model in response to Indian Ocean warming. Teleconnections due to the IOD may result from a Rossby wave train propagating from northeast of India to Canada [28].

Our study focuses on assessing the climatology and interannual variability of storm tracks from two long integrations of the National Center for Environmental Prediction (NCEP) Climate Forecast System version 1 from the Climate Model Intercomparison Projects one and two (labeled CMIP1 and CMIP2, resp.). These model simulations are similar, except for slightly different initial conditions.

We generated storm tracks over the entire length of each dataset (97 and 99 years, resp.) and compared frequency and intensity climatology with storm tracks generated from NCEP reanalysis I and ECMWF ERA40 data from 1958 to 2001. We also include results from high-resolution CFS reanalysis data from 1979 to 2009. For the remainder of the paper, we shall refer to storm tracks as "NCEP1" from NCEP's reanalysis dataset, "ERA40" from ECMWF's ERA40 reanalysis dataset, and "CFSR" from CFS reanalysis data.

In order to verify the ability of the CFS model to simulate interannual variability, we generate a seasonal Ocean Niño Index (ONI), North Atlantic Oscillation (NAO), and Indian Ocean Dipole (IOD) index from monthly CFS model data. Once we established the CFS model is able to simulate appropriate interannual variability, we evaluate the impacts of these indices on storm track frequency and intensity in the model. We then compare the results with the interannual responses from the reanalysis data to assess the ability of the CFS model to capture these responses.

Our paper is divided into the following sections. Section 2 describes the methodology. Section 3 describes the results including differences in climatology and interannual variability between the CFS model simulations and the reanalysis datasets. Section 4 offers a discussion and conclusion. 


\section{Data and Methodology}

To generate storm tracks, we use a Lagrangian method described in Serreze [29] and Serreze et al. [30] which tracks storms by locating an MSLP minimum within a given search radius. This method has been used frequently in the climate community. For example, Neu et al. [31] included this method in the Intercomparison of Mid-Latitude Storm Diagnostics (IMLAST) project, while Ulbrich et al. [32] used this method in an intercomparison of various storm tracking methodologies applied to the ECHAM5/OM1 model simulation using the SRES A1B scenario. Both Neu et al. [31] and Ulbrich et al. [32] found that differences between the algorithms occurred with counting weaker cyclones, while results were robust for stronger cyclones.

To assure temporal consistency in the coarse-gridded data, we generate storms from 6-hourly MSLP data for 19582001 in the NCEP1 and ERA40 datasets, which is on a $2.5^{\circ} \times$ $2.5^{\circ}$ (lat/lon) horizontal grid [33,34]. We also include storm tracks generated from 6-hourly MSLP from 1979 to 2009 for CFSR data, which has a $0.5^{\circ} \times 0.5^{\circ}$ (lat/lon) horizontal grid [35]. As discussed by Hodges et al. [36], the $\mathrm{NH}$ climatologies among several high-resolution datasets were in good agreement amongst each other and relative to a 25year coarse grid Japanese reanalysis dataset. We choose to show CFSR results to assess how the higher-resolution dataset produces interannual variability.

For model storm tracks, we use 6-hourly MSLP from CFS model version I described in Saha et al. [37]. The atmospheric component of the model has a T62 horizontal resolution, with 64 vertical layers. Although relatively coarse, Bengtsson et al. [13] points out that both the low and high resolutions of the ECHAM5 model produced comparable storm climatologies. Similar to Eichler and Higgins [21], we chose a one $\mathrm{hPa}$ threshold for finding storms and a maximum propagation distance of $800 \mathrm{~km}$ between timesteps. Although this is an overestimate of a distance a storm can travel between timesteps, it does allow for the possibility of center-jumps and also accounts for the gridded nature of the data we are using.

To determine seasonal storm track frequency climatology, we followed the methodology of Eichler and Higgins [21] of binning cyclone frequency into a $5^{\circ}$ latitude $\times 5^{\circ}$ longitude degree box, which is large enough to avoid too few storms being captured in the grid, while being small enough to avoid smoothing out of storm track features.

For cyclone intensity, we also used the methodology of Eichler and Higgins [21], which is summarized as follows. First, cyclone intensity (for each cyclone counted in the frequency climatology) was also binned into a $5^{\circ}$ latitude $\times 5^{\circ}$ longitude degree box. Next, we generated gridded, seasonal MSLP climatologies for each dataset. We then removed the trend for the climatological data for each grid box and subtracted from storm track data to determine cyclone intensity. In this way, we account for the latitudinal dependency of storms.

For the interannual variability portion of this work, we evaluated El Niño and the NAO with respect to $\mathrm{NH}$ winter storm tracks (JFM). For the IOD, we examined the effects from October to December (OND), since IOD has its greatest impact during northern hemisphere autumn [28]. To assess interannual variability, we perform two analyses: for storm track frequency, we employ a partial correlation analysis on El Niño, the IOD, and the NAO. Partial correlation allows the assessment of specific climate impacts on storm tracks by eliminating other potential causes. For example, since NAO and ENSO may both affect storm tracks, using partial correlation to eliminate $\mathrm{NAO}$ from an ENSO/ storm track frequency correlation ensures that ENSO is likely the overarching cause to changes in storm track frequency. Partial correlation was used by Ashok et al. [38] to determine the effects of IOD on SH storm tracks filtering out the effects of El Niño and vice-versa.

In a similar fashion, we generate storm track frequency correlations with respect to ENSO, IOD, and the NAO. Since IOD and El Niño are composed of SST, they represent external forcing to atmospheric phenomena such as storm tracks in the climate system. However, the NAO is derived from atmospheric variables (e.g., SLP or geopotential height), so it is representative of internal variability of the climate system. Because of this, we did not eliminate NAO in our IOD/El Niño correlation analysis. However, we eliminated El Niño and the IOD as external influences for the NAO correlation.

Since data is temporally discontinuous for intensity, our second method for evaluating interannual variability is via a composite analysis on storm intensity with respect to $\mathrm{El}$ Niño, the IOD, and the NAO. To evaluate ENSO in the reanalysis datasets, we used the ENSO Intensity Index (EIS) described in Kousky and Higgins [39]. We chose the EIS because it represents a simple five-class system of defining the strength of ENSO and is composed of the Oceanic Niño Index (ONI) which NOAA has adopted as its primary measure to evaluate and predict ENSO events [39]. The EIS is calculated by doubling the Oceanic Niño Index (ONI), defined as the 3 -month running mean of SST anomalies for the Niño3.4 region. The observed ONI is provided by the Climate Prediction Center [40].

We define El Niño/La Niña periods for seasonally averaged EIS values of greater than or equal to 2 and less than or equal to -2 , respectively. For the CFS model runs, we also calculate the ONI for each run. Since the El Niño criterion of Kousky and Higgins [39] may not apply to ENSO variability in the CFS model due to different ENSO variability in the CFS model relative to what is observed, we use a standard deviation (SD) cutoff for the ONI to determine El Niño/La Niña periods instead of the EIS index. We chose a $0.75 \mathrm{SD}$ cutoff to define El Niño/La Niña periods, with neutral periods defined in the range $\pm 0.5 \mathrm{SD}$. Although somewhat arbitrary, this choice ensures adequate sample size, while also providing separation between El Niño/La Niña episodes and neutral conditions. By doing this, we objectively separate observed ENSO variability from model-simulated ENSO variability.

For the NAO index, we used data derived from MSLP from $[41,42]$, while for the IOD, we utilized the index from Saji et al. [25], which calculates the IOD from SST data in the Indian Ocean [43]. For the CFS model simulations, we duplicated the NAO and IOD indices described above. Since EIS categories (i.e., from strong positive to strong negative) 


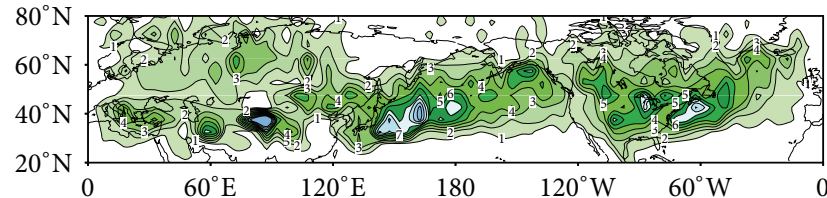

(a)

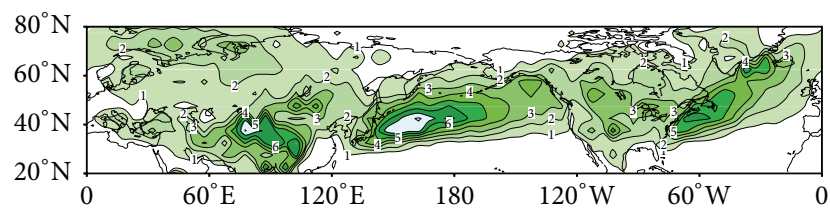

(c)

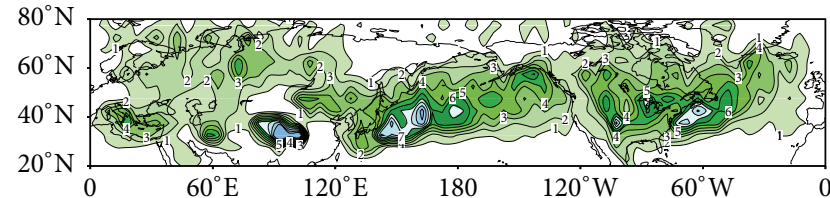

(b)

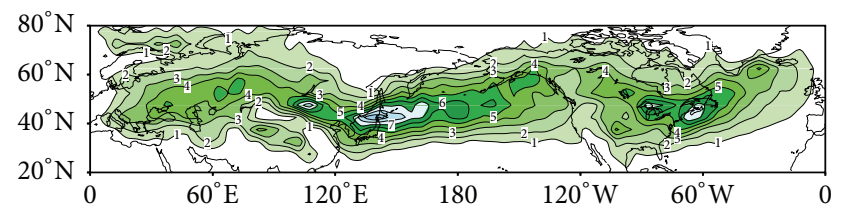

(d)

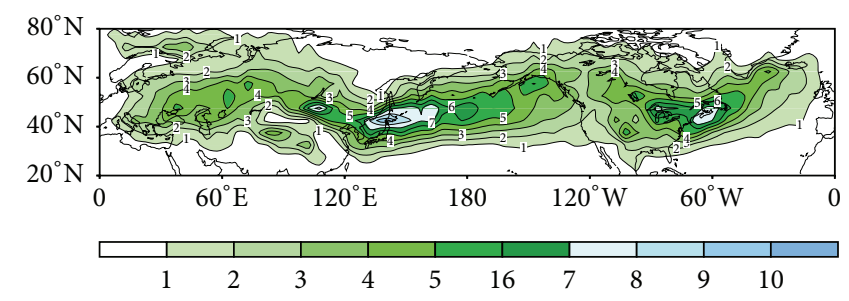

(e)

FIGURE 1: NH JFM storm track frequency climatology for (a) NCEP1, (b) ERA40, (c) CFSR, (d) CMIP1, and (e) CMIP2.

were not available for the NAO and IOD indices, we used the SD cutoffs defined for the CFS ONI for IOD and NAO for all reanalysis and model datasets.

To evaluate statistical significance of the composites, we applied the $t$ score used by Freund and Simon [44] and Bai et al. [45] to account for sample size difference in each grid box. A two-tailed 90 percent significance criterion was applied to each sample.

\section{Results}

3.1. Climatology. Figure 1 shows the JFM NH seasonal frequency climatologies for NCEP1, ERA40, CFSR, CMIP1, and CMIP2. There is good general agreement, with active storm track areas located in the North Pacific and North Atlantic for all reanalysis and model datasets (Figures 1(a)-1(e)). All datasets also show a local maximum in cyclones in the lee of the Rocky Mountains suggesting lee-side cyclogenesis, which is in agreement with Lambert et al. [11]. This is especially pronounced in the NCEP1 and ERA40 datasets relative to CFSR, CMIP1, and CMIP2, with NCEP1 and ERA40 showing a fairly well-defined track from the lee of the Rockies to the Great Lakes (compare Figures 1(a) and 1(b) with Figures 1(c)$1(\mathrm{e})$ ). Although it is not surprising that CMIP1 and CMIP2 show a somewhat weaker Lee-Cyclone track, it is surprising to see it in the CFSR given its higher spatial resolution. Further research is needed to further explore this, with an emphasis on CFS model physics and temporal sampling.

Storm track intensity climatology for JFM is displayed in Figure 2. For all model and reanalysis datasets, the Icelandic and Aleutian lows are well-represented with intensities of at least $20 \mathrm{hPa}$ below climatological mean (Figures 2(a)-2(e)).
The largest intensities for the Aleutian and Icelandic lows are shown for the CFSR storm tracks, with intensity exceeding $24 \mathrm{hPa}$ (Figure 2(c)). The more intense cyclones in the CFSR are likely due to its higher spatial resolution as suggested by Hodges et al. [36].

3.2. CFS Model Variability. Before we discuss the interannual variability of model-simulated storm tracks, it is useful to examine the CFS model's ability to simulate interannual variability. Wang et al. [46] examined an ensemble of 32-year runs of the CFS model to determine its ability to simulate ENSO. They found a peak variance of 3-5 years, similar to what is observed. Wang et al. [46] also determined that the amplitude of events was similar to strong events in the observation. Although Wang et al. [46] found that the modelsimulated ENSO was more regular than observed and that the variability of the amplitude was greater than observed, they concluded that the CFS model was suitable for seasonal prediction of interannual climate anomalies linked to ENSO. Time series of the CFS monthly ONI are shown in Figure 3. In both CMIP1 and CMIP2, a large interannual variation of $\mathrm{ONI}$ is evident, with peak events of approximately $2.5^{\circ} \mathrm{C}$ in both simulations (Figures 3(a) and 3(b)). To further examine the behavior of ENSO events, we constructed SST Hovmöller diagrams for 30-year periods containing strong events, which are shown in Figures 3(c) and 3(d). In both runs, strong events are clearly shown (e.g., years 2057 and 2036 for CMIP1 and CMIP2, resp.). An eastward propagation of the anomalies is also evident, which is consistent with Wang et al. [46].

To demonstrate SST anomalies associated with the IOD, we correlated the model-simulated IOD with SST for NH Fall (Figure 4). In both CMIP1 and CMIP2, a dipole structure is 


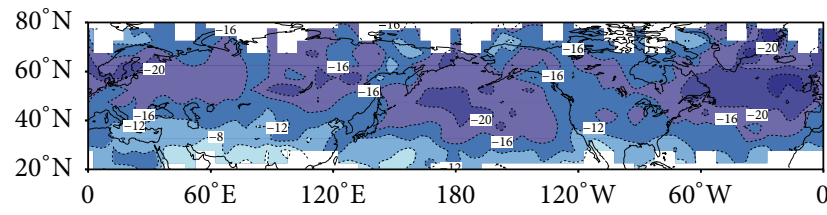

(a)

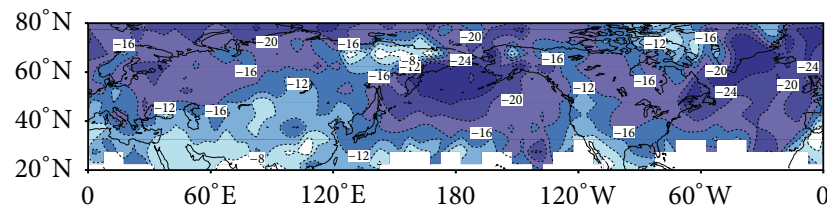

(c)

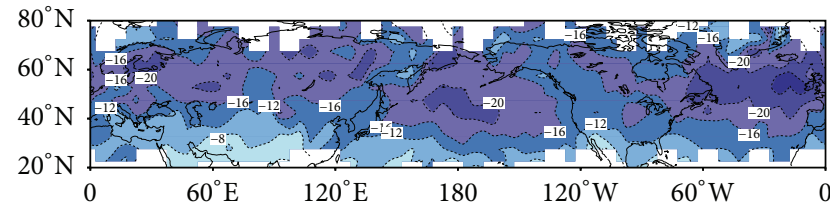

(b)

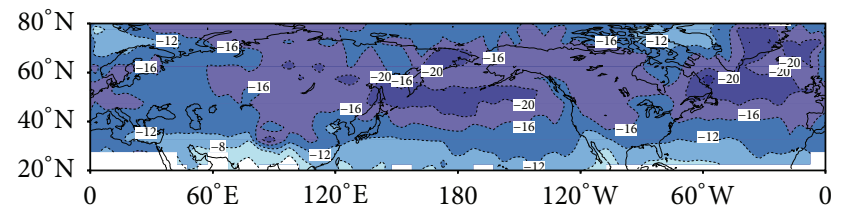

(d)

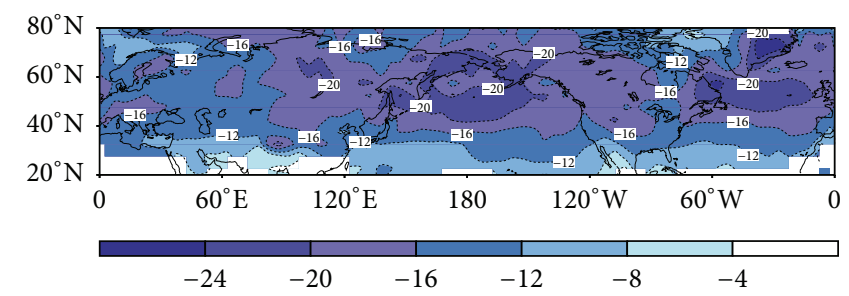

(e)

FIGURE 2: NH storm track intensity climatology for JFM (shaded). Intensity derived by subtracting regressed climatological mean from storm track mean (units: hPa) for (a) NCEP1, (b) ERA40, (c) CFSR, (d) CMIP1, and (e) CMIP2.

clearly seen, which resembles the mature phase of an IOD event described in Saji et al. [25].

Finally, we explored the CFS's model ability to simulate the NAO. Figures 5(a) and 5(b) show a point correlation of the NAO with SLP. An annular structure is evident in CMIP1 and CMIP2, with positive correlations at mid latitudes, and negative correlations at high latitudes. Not surprisingly, the strongest correlations are focused in the Atlantic/European sectors. The pattern shown agrees with Thejll et al. [47], who used NCEP reanalysis data to correlate NAO with SLP for 1973-2000.

All of the indices developed from the CFS model capture temporal and spatial structures similar to what is observed. Based on this, the CFS model is an appropriate tool to explore interannual variability related to storm tracks. In the following section, we will compare the response of the CFS model storm tracks to the above indices with results from our reanalysis datasets.

3.3. Interannual Variability: Frequency. To evaluate the relationship between storm track frequency and interannual variability, we employ the partial correlation technique described in Ashok et al. [38]. To assess the effects of El Niño on storm track frequency, we eliminate the IOD from the correlation. Similarly, we also eliminated El Niño from the IOD correlation. We decided against eliminating the NAO from these analyses, since the NAO is an internal manifestation of the climate system, instead of an external driver. However, we eliminate both El Niño and the IOD from the NAO correlation, since El Niño and the IOD are both external drivers. The partial correlation of storm track frequency with El Niño for the NH is shown in Figure 6. For NCEP1 and ERA40, the results are similar, with positive (negative) correlations in the mid-latitude North Pacific and from the Gulf of Mexico northward along the east coast and eastward into the North Atlantic (west of Alaska eastward to the northern U.S. into the North Atlantic) (Figures 6(a) and 6(b)). For the CFSR, the correlations (relative to NCEP1 and ERA40) are stronger in the North Pacific, with additional regions of positive correlation in Greenland and portions of China. The U.S. east coast response is also limited to the Gulf of Mexico in the CFSR (Figure 6(c)). At this time, it is difficult to ascertain if the differences are due to resolution or temporal sampling (e.g., more frequent El Niño events occurred in the 1980s and 1990s). Additional study is needed to compare the CFSR storm tracks to coarse-gridded reanalysis storm tracks of an identical time period, which is beyond the scope of this paper. Similarly (especially relative to NCEP1 and ERA40), though weaker responses to El Niño are obtained from CMIP1 (Figure 6(d)). Overall, the correlation pattern seen for NCEP1, ERA40, CFSR, and CMIP1 is consistent with the teleconnection pattern associated with El Niño featuring a positive Pacific North American (PNA) pattern [48] and a southward displacement of the polar jet in the North Pacific. They are also similar to the El Niño storm track composite described in Eichler and Higgins [21]. Negative correlations in all datasets from Alaska east-southeastward to the Great Lakes and east-northeastward to northeastern Canada indicate a dominant northern storm track during La Niña (Figure 6). For CMIP2, the response is somewhat different, with the positive correlations in the Gulf of Mexico not extending northeastward up the east coast, similar to 


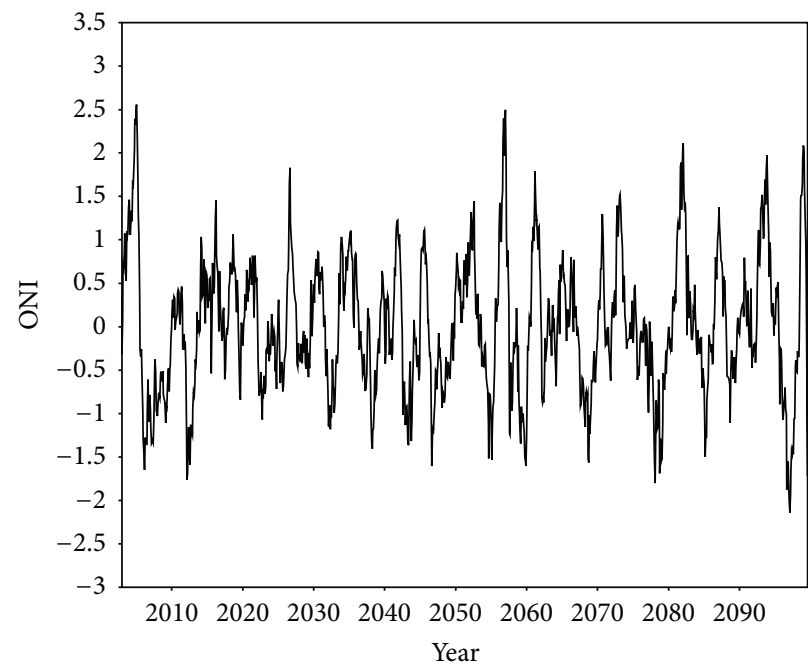

(a)

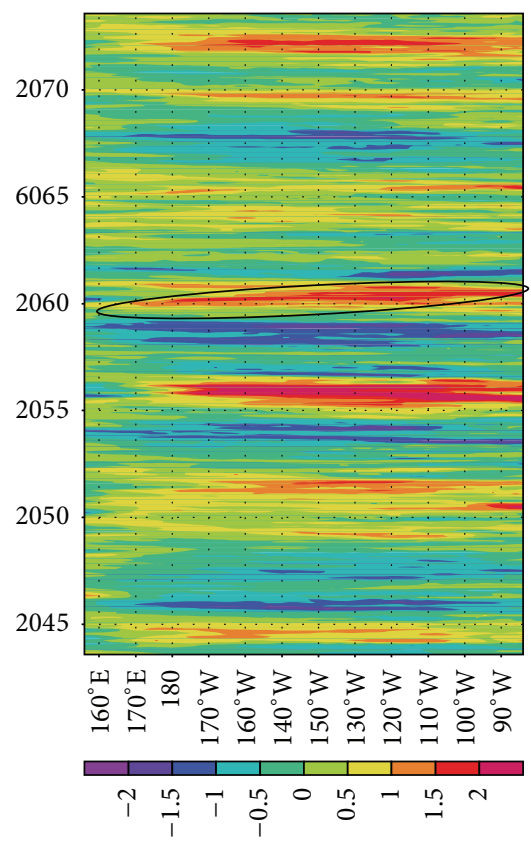

(c)

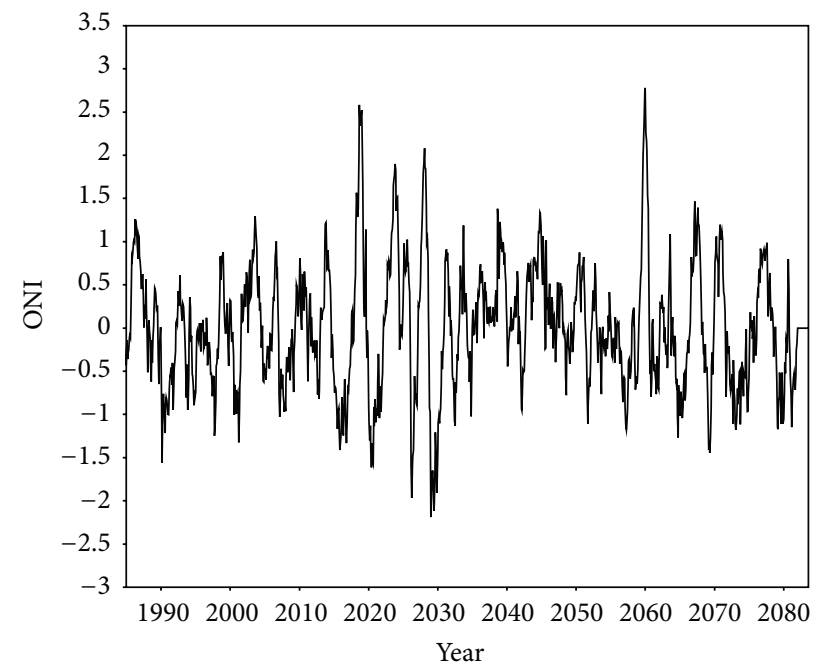

(b)

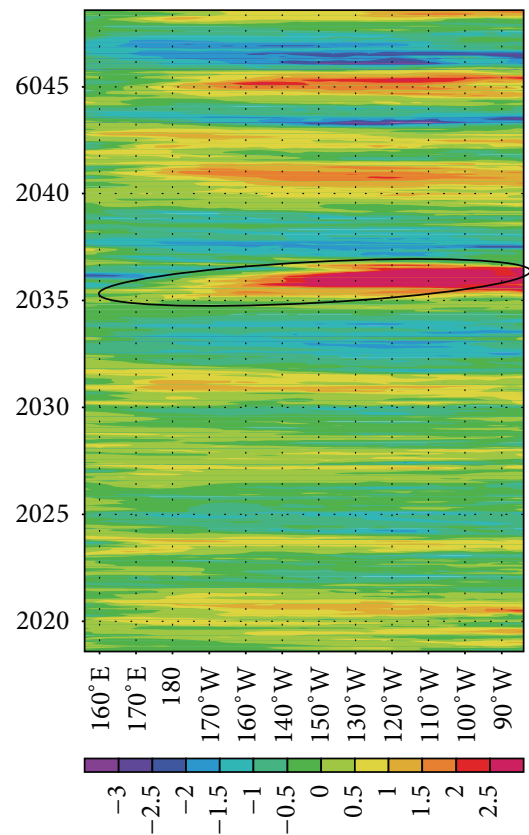

(d)

Figure 3: ONI for (a) CMIP1 and (b) like (a) but for CMIP2. (c) Hovmöeller SST diagram for CMIP1 and (d) like (c) but for CMIP2. Circled areas show a typical ENSO event.

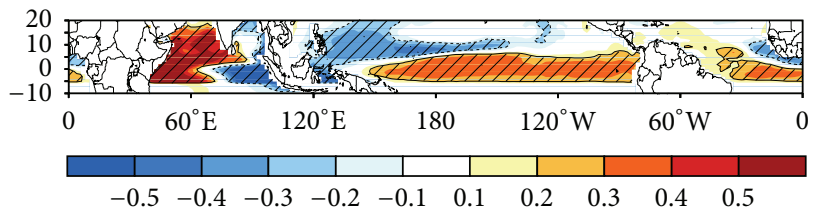

(a)

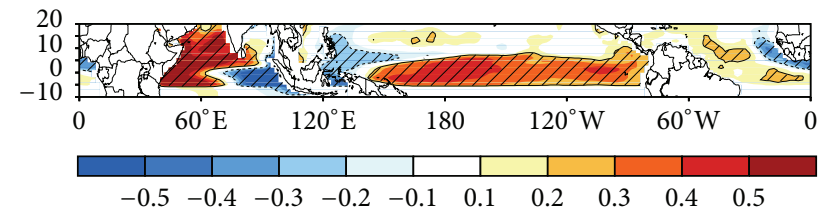

(b)

FIGURE 4: Correlation of IOD index with SST in OND for (a) CMIP1 and (b) CMIP2. Significance at 95\% (hatched). 


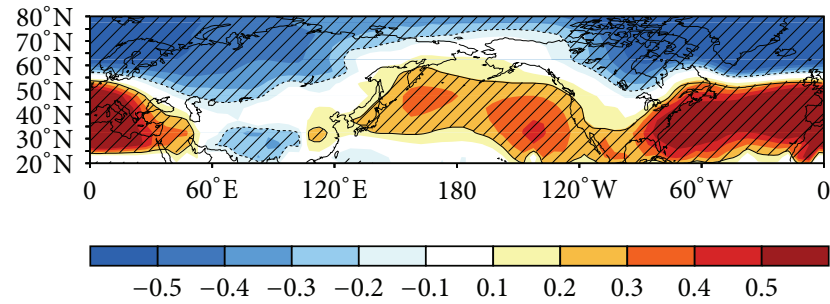

(a)

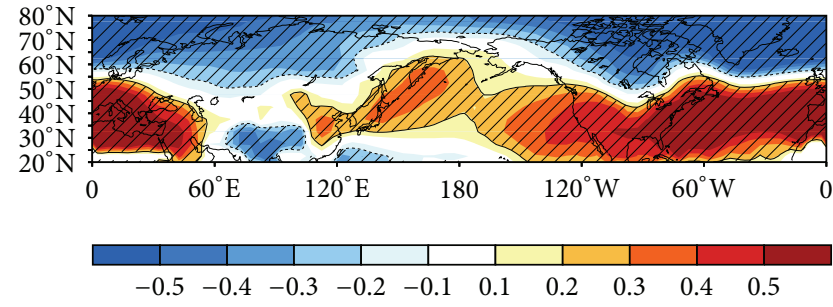

(b)

FIGURE 5: Correlation of NAO with NH SLP for JFM from (a) CMIP1 and (b) like (a) but for CMIP2 significance at 95\% (hatched).

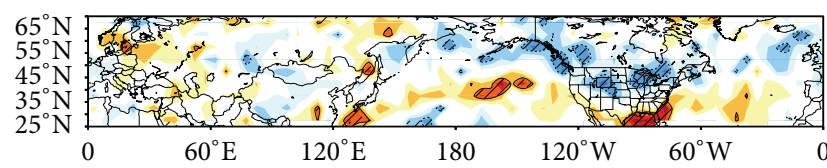

(a)

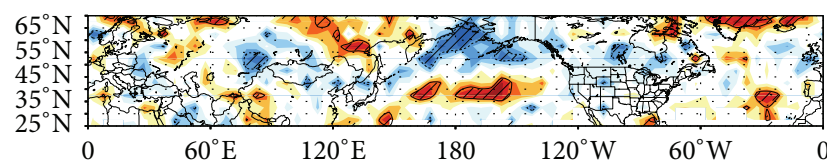

(c)

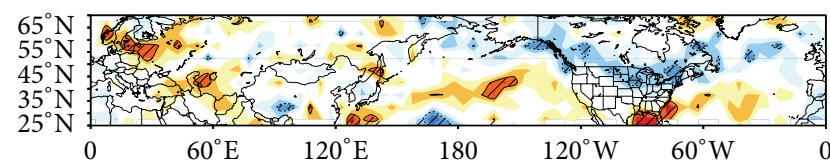

(b)

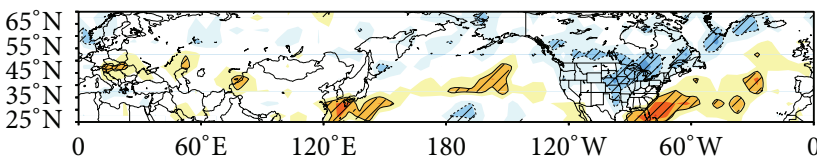

(d)

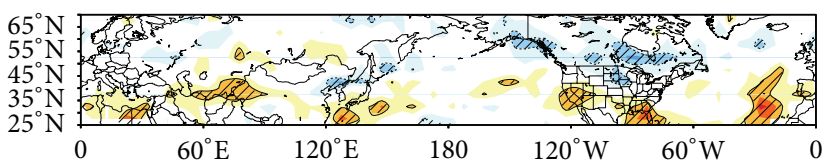

(e)

FIGURE 6: Partial correlation coefficient for storm frequency versus El Niño for NH in JFM (excluding IOD). Correlation (shaded), 95\% significance (hatched) for (a) NCEP1, (b) ERA40, (c) CFSR, (d) CMIP1, and (e) CMIP2.

CFSR (compare Figure 6(c) with Figure 6(e)). Positive correlations are also lacking in the North Pacific for CMIP2, while positive correlations occur in the Mediterranean eastward across northern China in CMIP2 relative to CMIP1 (compare Figure 6(d) with Figure 6(e)). While it is encouraging that there is a fair amount of agreement between the model simulations (especially CMIP1) and the reanalysis datasets, the lack of robustness between CMIP1 and CMIP2 suggests that caution is advised when assessing interannual variability in the CFS model. Perhaps coarse model resolution plays a role.

For the IOD, the correlation pattern in the NCEP1 and ERA40 datasets shows negative, though nonsignificant correlations from Japan northeastward to the Gulf of Alaska (Figures 7(a) and 7(b)). There is also a hint of a wave-like structure with negative (positive) correlations across western Canada and the Great Lakes (central Canada), with a small area in the Great Lakes being significant (Figures 7(a) and 7(b)). This is much more pronounced in the CFSR dataset (except the Great Lakes negative correlation), with a tripole structure in the N. Pacific consisting of positive correlation from east of northern Japan to the Pacific northwest, straddled on either side by negative correlations (Figure 7(c)). The positive (negative) correlation over south-Central Canada (eastern Canada) in the CFSR is similar, though shifted slightly east of the IOD frequency composite described in Eichler and Gottschalck [49], and may be the result of Rossby wave propagation from anomalous heating in the Indian Ocean as reported by Saji and Yamagata [26], Min et al. [28], and Small et al. [50]. It would be interesting to further investigate this possibility with a more extensive dataset (e.g., NCEP's reforecast data).

The CMIP1 and CMIP2 IOD correlation maps do not agree well with the reanalysis datasets. For example, CMIP1 and CMIP2 exhibit positive correlations in Japan, while they are negative in NCEP1 and ERA40, with little correlation in the CFSR (compare Figures 7(a)-7(c) with Figures 7(d) and 7(e)). CMIP2 also shows a rather extensive area of positive correlations from the Gulf of Alaska eastward into the Arctic, which are nonexistent in all of the other results (compare Figure $7(\mathrm{e})$ with Figures $7(\mathrm{a})-7(\mathrm{~d})$ ). The only similarity is an area of positive correlation across central Canada in CMIP1, which agrees fairly well (slightly displaced west) with the reanalysis datasets (compare Figure 7(d) with Figures 7(a)$7(\mathrm{c})$ ). The poor agreement between the CFS model and reanalysis datasets may be due to the inability of the CFS model to generate remote teleconnections to a more localized anomalous heating source (i.e., the IOD) than ENSO. 


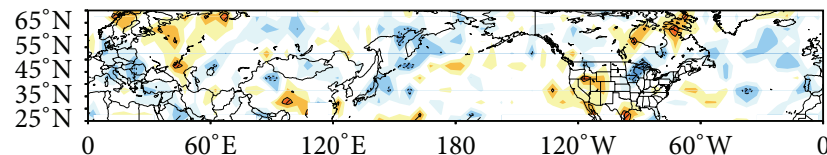

(a)

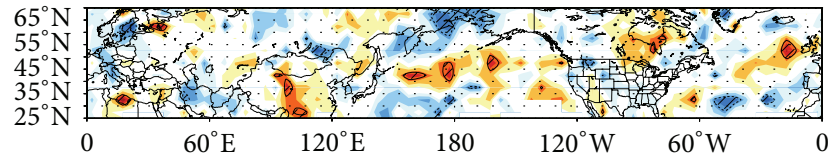

(c)

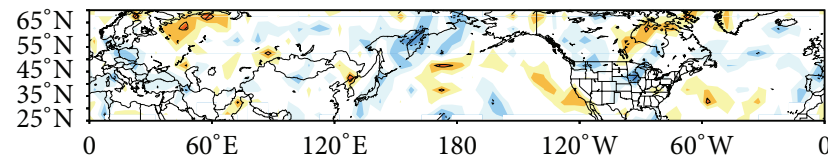

(b)

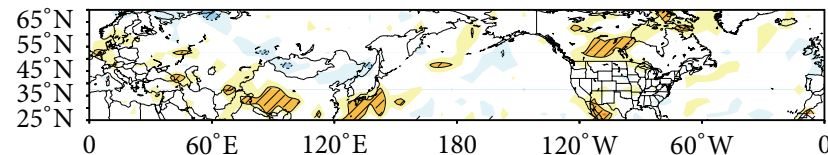

(d)

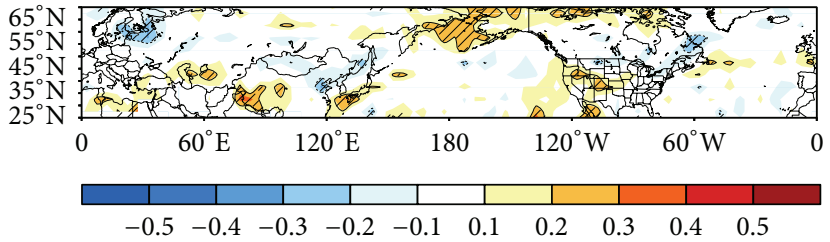

(e)

Figure 7: Partial correlation coefficient for storm frequency versus IOD for NH in OND (excluding El Niño). Correlation (shaded), 95\% significance (hatched) for (a) NCEP1, (b) ERA40, (c) CFSR, (d) CMIP1, and (e) CMIP2.

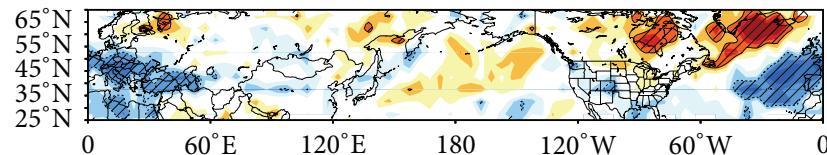

(a)

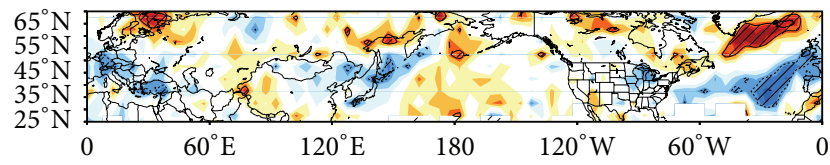

(c)

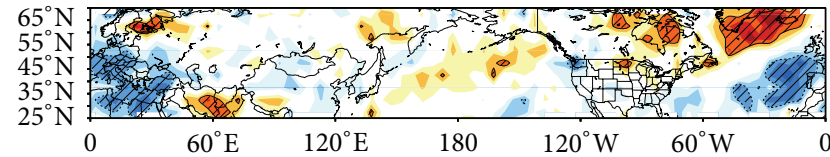

(b)

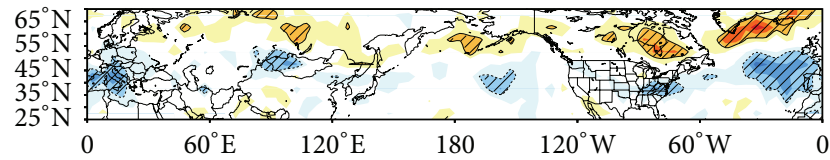

(d)

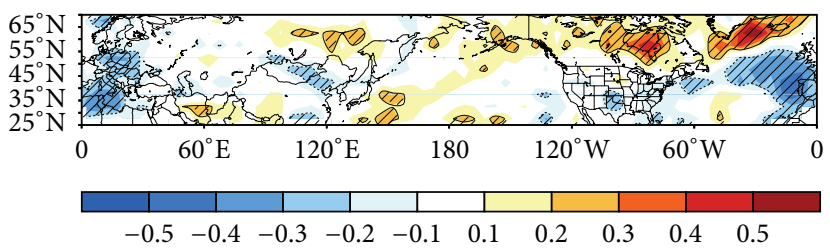

(e)

FIGURE 8: Partial correlation coefficient for storm frequency versus NAO for NH in JFM (excluding IOD and El Niño). Correlation (shaded), 95\% significance (hatched) for (a) NCEP1, (b) ERA40, (c) CFSR, (d) CMIP1, and (e) CMIP2.

Unlike the IOD, NAO-induced storm tracks show a similar pattern for all datasets, with positive correlations south of Greenland and negative correlations across the midlatitude North Atlantic eastward across Europe (Figure 8). This result is not surprising, since storm tracks and the NAO are both composed of SLP. Interestingly, positive correlations are also quite evident away from the NAO centers of action across much of Canada and the North Pacific in the reanalysis datasets (Figures 8(a)-8(c)), although the positive correlation in Canada is weaker in the CFSR datasets NCEP1 and ERA40 (Figure $8(\mathrm{c})$ ). These features are also seen in CMIP1 (Figures $8(\mathrm{~d})$ and $8(\mathrm{e})$ ). Although the areas of significant correlation distant from NAO centers of action may have been due to contamination of the NAO signal from other sources such as ENSO, partial correlation eliminates this possibility. Instead, our results suggest that NAO by itself is part of a larger teleconnection pattern impacting storm tracks on a hemispheric scale. 


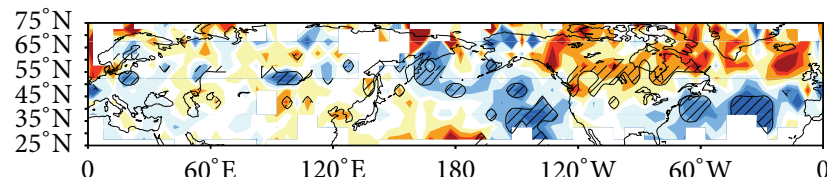

(a)

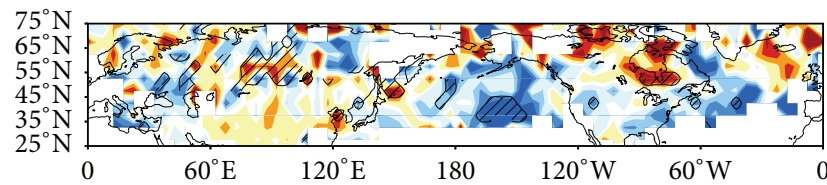

(c)

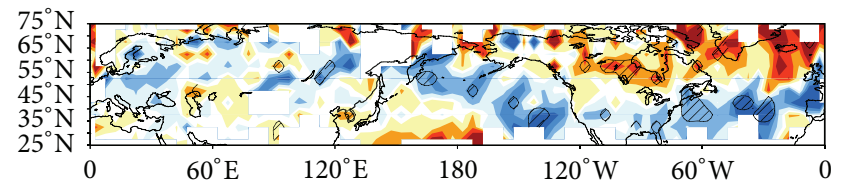

(b)

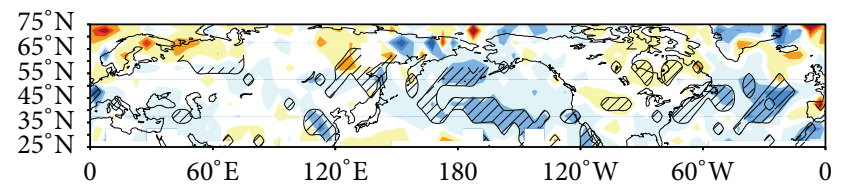

(d)

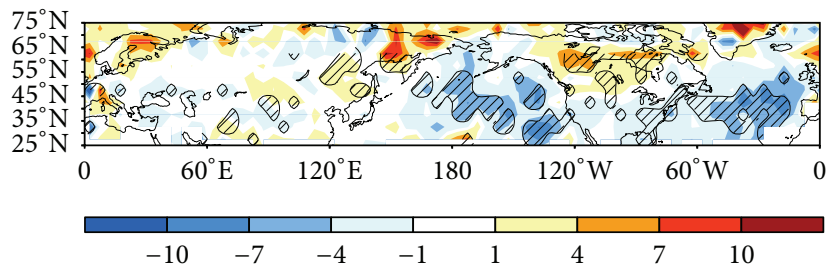

(e)

FIGURE 9: NH storm track intensity composite (hPa) in JFM for (a) El Niño relative to La Niña (shaded) 95\% significance (hatched) for (a) NCEP1, (b) like (a) but for ERA40, (c) like (a) but for CFSR, (d) like (a) but for CMIP1, and (e) like (a) but for CMIP2.

3.4. Interannual Variability: Intensity. Intensity composites for El Niño relative to La Niña show that stronger (weaker) storms occur across much of the $\mathrm{NH}$ mid latitudes $\left(40^{\circ} \mathrm{N}-\right.$ $45^{\circ} \mathrm{N}$ ) and weaker (stronger) storms in the polar latitudes $\left(70^{\circ} \mathrm{N}\right)$, especially in the North Atlantic during El Niño (La Niña) for the reanalysis datasets (Figures 9(a)-9(c)). Interestingly, the dipole structure in the North Atlantic resembles the negative NAO, which agrees with Rogers [51], who related the Southern Oscillation (SO) to the NAO. A similar pattern is seen for CMIP2 but is much weaker in CMIP1 (Figures 9(d) and 9(e)).

Intensity composites for the positive NAO shows stronger (weaker) storms in the high latitude North Atlantic and weaker (stronger) storms in the mid-latitude North Atlantic corresponding to the positive (negative) phase of the NAO (Figures 10(a)-10(e)). As was discussed with the NAO frequency analysis, the impacts of NAO extend away from the NAO centers of action, with stronger storms extending across much of the polar region north of $65^{\circ} \mathrm{N}$ for all datasets (Figures 10(a)-10(e)). A difference between model and reanalysis datasets is seen over the Mediterranean Sea, where weaker storms (positive NAO relative to negative $\mathrm{NAO}$ ) occur in the reanalysis datasets, especially near the north shore of the Mediterranean Sea in the CFSR, but to a lesser degree in CMIP2 and not at all in CMIP1 (compare Figures 10(a)-10(c) with Figures 10(d) and 10(e)).

The response of $\mathrm{NH}$ storm track intensity to the IOD is fairly weak, although a positive IOD tends to produce more intense storms in the central North Pacific and central North Atlantic at approximately $50^{\circ} \mathrm{N}$ in the reanalysis datasets (Figures 11(a)-11(c)). In CMIP1 and CMIP2, this is absent, although CMIP2 shows an area of more intense storms in the North Atlantic along $50^{\circ} \mathrm{N}$ (Figures $11(\mathrm{~d})$ and $11(\mathrm{e})$ ). In contrast, CMIP2 produces less intense storms in the North Pacific (Figure 11(e)).

Since the response of storm intensity to IOD is rather muted even in the reanalysis datasets, this points to the IOD impact being limited in the NH. Given the remoteness and more local nature of anomalous heating produced by the IOD relative to ENSO, it is not surprising that the effects of the IOD on storm tracks are rather weak, especially in the CFS model simulations. It would be interesting to reassess potential IOD impacts in higher-resolution model and reanalysis products, as well as data of greater statistical relevance such as NCEP's reforecast data.

\section{Conclusions}

CMIP1 and CMIP2 produced similar storm track frequency climatologies to the reanalysis datasets for JFM, with a maximum frequency of storm tracks in the North Pacific and North Atlantic. For NH JFM intensity climatology, all reanalysis and model datasets prominently showed the Aleutian and Icelandic lows. The CFSR had more intense storms in the vicinity of the Icelandic and Aleutian lows, likely due to the higher spatial resolution of the CFSR dataset relative to the other reanalysis and model datasets. All reanalysis/model datasets showed a lee-side storm track from east of the Rockies northeastward to the Great Lakes, with this track being especially pronounced in NCEP1 and ERA40.

Assessment of indices such as ONI, NAO, and the IOD demonstrate that the CFS model is capable of simulating these aspects of interannual variability. An examination of equatorial SST anomalies showed that the CFS model produces an ENSO-like response, with a tendency towards eastward propagation. 


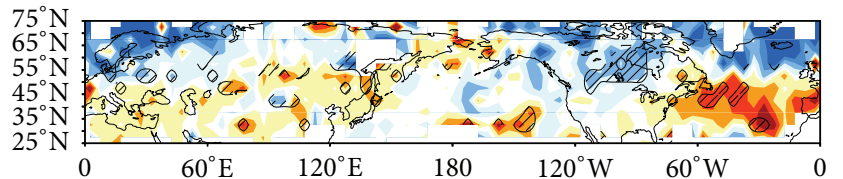

(a)

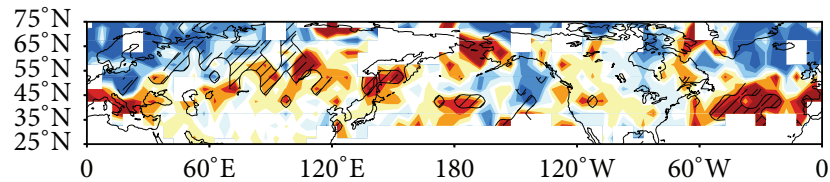

(c)

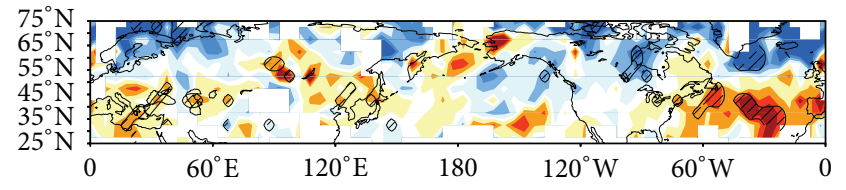

(b)

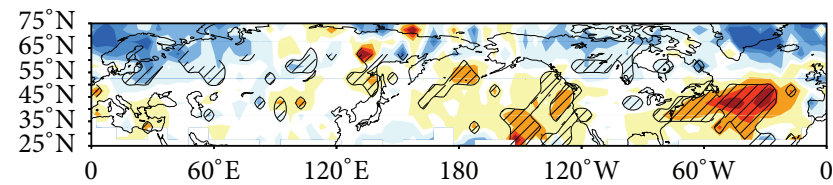

(d)

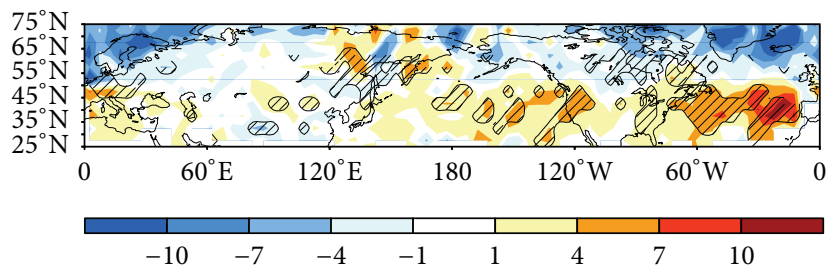

(e)

FIGURE 10: NH storm track intensity composite (hPa) in JFM for (a) NAO positive relative to NAO negative (shaded) $95 \%$ significance (hatched) for (a) NCEP1, (b) like (a) but for ERA40, (c) like (a) but for CFSR, (d) like (a) but for CMIP1, and (e) like (a) but for CMIP2.

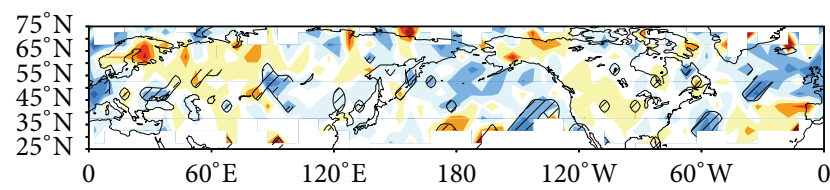

(a)

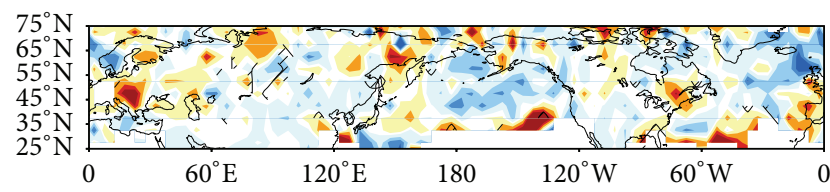

(c)

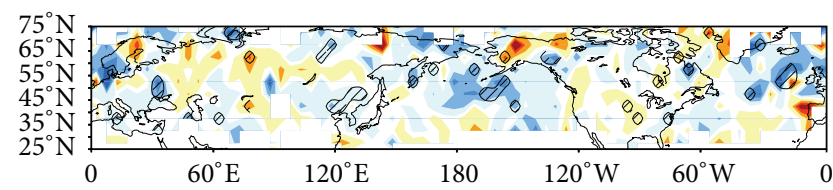

(b)

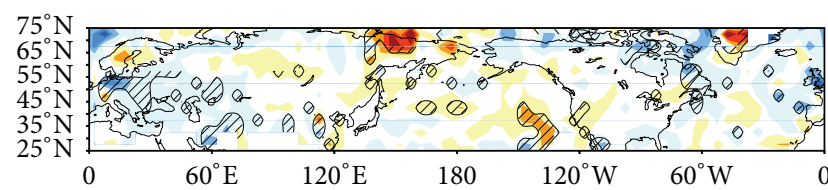

(d)

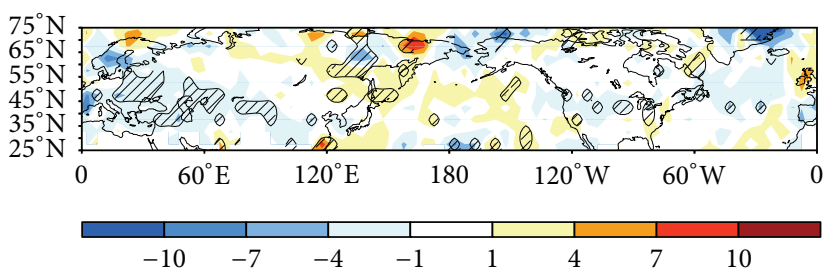

(e)

FIGURE 11: NH storm track intensity composite (hPa) in OND for (a) DMI positive relative to DMI negative (shaded) $95 \%$ significance (hatched) for (a) NCEP1, (b) like (a) but for ERA40, (c) like (a) but for CFSR, (d) like (a) but for CMIP1, and (e) like (a) but for CMIP2.

The response of $\mathrm{NH}$ storm track frequency as a function of El Niño showed increased (decreased) storm track frequency in the mid-latitude North Pacific and along the east coast of the U.S., with decreased (increased) storm tracks from Alaska eastward to the south of Greenland during El Niño (La Niña) for both reanalysis datasets similar to Eichler and Higgins [21]. For CMIP1, the results are similar to both reanalysis datasets. However, CMIP2 failed to produce positive correlations up the U.S. east coast and exhibited a less well-defined area of positive correlation in the North Pacific. Interestingly, the CFSR dataset also had the eastern U.S. positive correlation limited to the Gulf of Mexico. Inconsistency in the response of CMIP1 and CMIP2 to El Niño suggests that the CFS model exhibits a large sensitivity 
to external conditions of the same magnitude as El Niño variability. Higher resolution, more ensemble members and longer integration times may help resolve these differences.

Though the IOD showed the weakest impact on $\mathrm{NH}$ storm tracks, some interesting features were evident. For example, negative (positive) correlations across western Canada and the Great Lakes (central Canada) in the reanalysis datasets (especially the CFSR) suggest a wave-like response of IOD to storm tracks possibly resulting from Rossby wave propagation due to anomalous heating in the Indian Ocean. A tripole structure was also noted in the North Pacific in the CFSR dataset. Neither CFS model simulation showed this feature. Future work investigating a more extensive dataset such as NCEP's reforecast data may help to further clarify the impacts of the IOD on storm tracks.

Not surprisingly, the NAO showed the strongest impact on NH storm tracks. More (less) frequent storms occurred south of Greenland, with less (more) frequent storms from the mid-latitude North Atlantic to southern Europe during positive (negative) NAO. Impacts of the NAO on storm tracks were found in other regions besides the regions closest to the NAO centers of action. Considering that El Niño and the IOD were filtered out of the analysis, our results demonstrate a hemispheric-scale response of storm tracks to the NAO.

Storm track intensity composites for El Niño showed stronger (weaker) storms in the $\mathrm{NH}$ mid-latitudes from $40^{\circ} \mathrm{N}-45^{\circ} \mathrm{N}$, with weaker (stronger) storms along $70^{\circ} \mathrm{N}$ in response to El Niño (La Niña). A dipole structure in the North Atlantic resembled the NAO. These features generally occurred in all datasets, although it was much weaker in CMIP2.

The NAO's effect on NH storm track intensity was a mirror image in the North Atlantic, with weaker (stronger) storms in high- (mid-) latitudes during negative (positive) NAO. Similar to NAO's frequency response, stronger storms were found away from the NAO's centers of action in the polar region north of $65^{\circ} \mathrm{N}$ and across the Gulf of Mexico into the North Atlantic. The latter is consistent with a southern storm track resulting from high-latitude blocking associated with the negative NAO.

For the IOD, more intense storms occurred during positive IOD at $50^{\circ} \mathrm{N}$ in the central North Pacific and central North Atlantic in the reanalysis datasets, which was not seen in either model simulation. Our results suggest that teleconnections related to the IOD may be too far removed from influencing NH storm tracks in the models. We are currently assessing if the IOD has a greater impact on SH storm tracks.

Overall, our results demonstrate that the CFS model is capable of producing realistic storm track frequency and intensity climatologies. Although the model produces reasonable indices of interannual variability, the model's response to the indices ranges from excellent to nonexistent. The best responses are to NAO and ENSO, with the IOD being the weakest. Our results suggest that the CFS's model's storm track response improves as a function of the strength of external forcing. It appears that the IOD produces heating that is too remote for the CFS model to react. Further study is needed to evaluate the physical mechanisms related to the CFS's interannual variability. Since the IOD's impact on storm tracks is even difficult to detect in the reanalysis datasets, higher resolution and more extensive datasets such as NCEP's reforecast data would be useful in further isolating any potential impacts from the IOD. Since both model simulations did not always exhibit the same storm track interannual variability, analysis of higher resolution multimodel ensembles would aid in further quantifying model-generated interannual variability related to storm tracks.

\section{Disclaimer}

Any opinions, findings, and conclusions or recommendations expressed in this material are those of the authors and do not necessarily reflect the views of the National Science Foundation.

\section{Conflict of Interests}

The authors declare no conflict of interests.

\section{Acknowledgment}

This study is partly supported by the National Science Foundation under Award no. IIA-1355406.

\section{References}

[1] E. K. M. Chang and Y. F. Fu, "Using mean flow change as a proxy to infer interdecadal storm track variability," Journal of Climate, vol. 16, no. 13, pp. 2178-2196, 2003.

[2] S. Petterson, "Some aspects of the general circulation of the atmosphere," in Centenary Proceedings of the Royal Meteorological Society, pp. 120-155, Royal Meteorological Society, London, UK, 1950.

[3] W. H. Klein, "Principal tracks and mean frequencies of cyclones and anticyclones in the Northern Hemisphere," Research Paper 40, Weather Bureau, Washington, DC, USA, 1957.

[4] C. H. Reitan, "Frequencies of cyclones and cyclogenesis for North America, 1951-1970," Monthly Weather Review, vol. 102, no. 12, pp. 861-868, 1974.

[5] K. M. Zishka and P. J. Smith, “The climatology of cyclones and anticyclones over North America and surrounding ocean environs for January and July 1950-77," Monthly Weather Review, vol. 108, no. 4, pp. 387-401, 1980.

[6] N.-C. Lau and M. J. Nath, "Frequency dependence of the structure and temporal development of wintertime tropospheric fluctuations-comparison of a GCM simulation with observations," Monthly Weather Review, vol. 115, no. 1, pp. 251-271, 1987.

[7] J. S. Frederiksen and C. S. Frederiksen, "Southern Hemisphere storm tracks, blocking, and low-frequency anomalies in a primitive equation model," Journal of the Atmospheric Sciences, vol. 50, no. 18, pp. 3148-3163, 1993.

[8] C. S. Frederiksen and J. S. Frederiksen, "A theoretical model of Australian northwest cloudband disturbances and Southern Hemisphere storm tracks: the role of SST anomalies," Journal of the Atmospheric Sciences, vol. 53, no. 10, pp. 1410-1432, 1996.

[9] E. K. M. Chang, "Characteristics of wave packets in the upper troposphere. Part II: seasonal and hemispheric variations," Journal of the Atmospheric Sciences, vol. 56, no. 11, pp. 1729-1747, 1999. 
[10] L. S. Graff and J. H. LaCasce, "Changes in the extratropical storm tracks in response to changes in SST in an AGCM," Journal of Climate, vol. 25, no. 6, pp. 1854-1870, 2012.

[11] S. Lambert, J. Sheng, and J. Boyle, "Winter cyclone frequencies in thirteen models participating in the atmospheric model intercomparison project (AMIP1)," Climate Dynamics, vol. 19, no. 1, pp. 1-16, 2002.

[12] L. Bengtsson, K. I. Hodges, and E. Roeckner, "Storm tracks and climate change," Journal of Climate, vol. 19, no. 15, pp. 3518-3543, 2006.

[13] L. Bengtsson, K. I. Hodges, and N. Keenlyside, "Will extratropical storms intensify in a warmer climate?" Journal of Climate, vol. 22, no. 9, pp. 2276-2301, 2009.

[14] C. Z. Greeves, V. D. Pope, R. A. Stratton, and G. M. Martin, "Representation of Northern Hemisphere winter storm tracks in climate models," Climate Dynamics, vol. 28, no. 7-8, pp. 683702, 2007.

[15] C. C. Raible, P. M. Della-Marta, C. Schwierz, H. Wernli, and R. Blender, "Northern Hemisphere extratropical cyclones: a comparison of detection and tracking methods and different reanalyses," Monthly Weather Review, vol. 136, no. 3, pp. 880-897, 2008.

[16] G. A. Meehl, C. Covey, K. E. Taylor et al., “The WCRP CMIP3 multimodel dataset: a new era in climate change research," Bulletin of the American Meteorological Society, vol. 88, no. 9, pp. 1383-1394, 2007.

[17] Q. Geng and M. Sugi, "Possible change of extratropical cyclone activity due to enhanced greenhouse gases and sulfate aerosols-study with a high-resolution AGCM," Journal of Climate, vol. 16, no. 13, pp. 2262-2274, 2003.

[18] I. G. Watterson, "The intensity of precipitation during extratropical cyclones in global warming simulations: a link to cyclone intensity?" Tellus Series A: Dynamic Meteorology and Oceanography, vol. 58, no. 1, pp. 82-97, 2006.

[19] J. L. Catto, L. C. Shaffrey, and K. I. Hodges, "Can climate models capture the structure of extratropical cyclones?" Journal of Climate, vol. 23, no. 7, pp. 1621-1635, 2010.

[20] E. K. M. Chang, S. Lee, and K. L. Swanson, "Storm track dynamics," Journal of Climate, vol. 15, no. 16, pp. 2163-2183, 2002.

[21] T. Eichler and W. Higgins, "Climatology and ENSO-related variability of North American extratropical cyclone activity," Journal of Climate, vol. 19, no. 10, pp. 2076-2093, 2006.

[22] J. Lu, G. Chen, and D. M. W. Frierson, "Response of the zonal mean atmospheric circulation to El Niño versus global warming," Journal of Climate, vol. 21, no. 22, pp. 5835-5851, 2008.

[23] J. A. Bradbury, B. D. Keim, and C. P. Wake, "The influence of regional storm tracking and teleconnections on winter precipitation in the northeastern United States," Annals of the Association of American Geographers, vol. 93, no. 3, pp. 544-556, 2003.

[24] R. Seager, Y. Kushnir, J. Nakamura, M. Ting, and N. Naik, "Northern Hemisphere winter snow anomalies: ENSO, NAO and the winter of 2009/10," Geophysical Research Letters, vol. 37, no. 14, Article ID L14703, 2010.

[25] N. H. Saji, B. N. Goswami, P. N. Vinayachandran, and T. Yamagata, "A dipole mode in the tropical Indian ocean," Nature, vol. 401, no. 6751, pp. 360-363, 1999.

[26] N. H. Saji and T. Yamagata, "Possible impacts of Indian Ocean dipole mode events on global climate," Climate Research, vol. 25, no. 2, pp. 151-169, 2003.
[27] H. Annamalai, K. Hamilton, and K. R. Sperber, “The South Asian summer monsoon and its relationship with ENSO in the IPCC AR4 simulations," Journal of Climate, vol. 20, no. 6, pp. 1071-1092, 2007.

[28] J. Min, Q. Zhou, N. Liu, Q. Gao, and Z. Guan, "Teleconnection mode between IOD and Northern Hemisphere tropospheric circulation and its mechanism," Meteorology and Atmospheric Physics, vol. 100, no. 1-4, pp. 207-215, 2008.

[29] M. C. Serreze, "Climatological aspects of cyclone development and decay in the arctic," Atmosphere-Ocean, vol. 33, no. 1, pp. $1-23,1995$.

[30] M. C. Serreze, F. Carse, R. G. Barry, and J. C. Rogers, "Icelandic low cyclone activity: climatological features, linkages with the $\mathrm{NAO}$, and relationships with recent changes in the Northern Hemisphere circulation," Journal of Climate, vol. 10, no. 3, pp. 453-464, 1997.

[31] U. Neu, M. G. Akperov, N. Bellenbaum et al., "IMILAST: a community effort to intercompare extratropical cyclone detection and tracking algorithms," Bulletin of the American Meteorological Society, vol. 94, no. 4, pp. 529-547, 2013.

[32] U. Ulbrich, G. Leckebusch, J. Grieger et al., "Are greenhouse gas signals of Northern Hemisphere winter extra-tropical cyclone activity dependent on the identification and tracking methodology?" Meteorologische Zeitschrift, vol. 22, pp. 61-68, 2013.

[33] E. Kalnay, M. Kanamitsu, R. Kistler et al., "The NCEP/NCAR 40-year re-analysis project," Bulletin of the American Meteorological Society, vol. 77, no. 3, pp. 437-471, 1996.

[34] S. M. Uppala, P. W. Kållberg, A. J. Simmons et al., “The ERA40 re-analysis," Quarterly Journal of the Royal Meteorological Society, vol. 131, no. 612, pp. 2961-3012, 2005.

[35] S. Saha, S. Moorthi, H.-L. Pan et al., “The NCEP climate forecast system reanalysis," Bulletin of the American Meteorological Society, vol. 91, no. 8, pp. 1015-1057, 2010.

[36] K. I. Hodges, R. W. Lee, and L. Bengtsson, "A comparison of extratropical cyclones in recent reanalyses ERA-Interim, NASA MERRA, NCEP CFSR, and JRA-25," Journal of Climate, vol. 24, no. 18, pp. 4888-4906, 2011.

[37] S. Saha, S. Nadiga, C. Thiaw et al., "The NCEP climate forecast system," Journal of Climate, vol. 19, no. 15, pp. 3483-3517, 2006.

[38] K. Ashok, H. Nakamura, and T. Yamagata, "Impacts of ENSO and Indian Ocean dipole events on the Southern Hemisphere storm-track activity during austral winter," Journal of Climate, vol. 20, no. 13, pp. 3147-3163, 2007.

[39] V. E. Kousky and R. W. Higgins, "An alert classification system for monitoring and assessing the ENSO cycle," Weather and Forecasting, vol. 22, no. 2, pp. 353-371, 2007.

[40] ONI Data, http://www.cpc.ncep.noaa.gov/products/analysis_ monitoring/ensostuff/ensoyears_1971-2000_climo.shtml.

[41] P. D. Jones, T. Jónsson, and D. Wheeler, "Extension to the North Atlantic oscillation using early instrumental pressure observations from Gibraltar and south-west Iceland," International Journal of Climatology, vol. 17, no. 13, pp. 1433-1450, 1997.

[42] NAO Data, http://www.cru.uea.ac.uk/cru/data/nao.

[43] IOD Data, http://www.jamstec.go.jp/frcgc/research/d1/iod/ kaplan_sst_dmi_new.txt.

[44] J. E. Freund and G. A. Simon, Modern Elementary Statistics, Prentice Hall, Englewood Cliffs, NJ, USA, 8th edition, 1992.

[45] X. Bai, J. Wang, C. Sellinger, A. Clites, and R. Assel, "Interannual variability of Great Lakes ice cover and its relationship to NAO and ENSO," Journal of Geophysical Research C: Oceans, vol. 117, no. 3, Article ID C03002, 2012. 
[46] W. Wang, S. Saha, H.-L. Pan, S. Nadiga, and G. White, "Simulation of ENSO in the new NCEP coupled forecast system model (CFS03)," Monthly Weather Review, vol. 133, no. 6, pp. 15741593, 2005.

[47] P. Thejll, B. Christiansen, and H. Gleisner, "On correlations between the North Atlantic oscillation, geopotential heights, and solar-activity proxies," Geophys. Res. Lett, vol. 30, p. 1347, 2003.

[48] J. M. Wallace and D. S. Gutzler, "Teleconnections in the geopotential height field during the Northern Hemisphere winter," Monthly Weather Review, vol. 109, no. 4, pp. 784-812, 1981.

[49] T. P. Eichler and J. Gottschalck, "Interannual variability of northern hemisphere storm tracks in coarse-gridded datasets," Advances in Meteorology, vol. 2013, Article ID 545463, 15 pages, 2013.

[50] D. Small, S. Islam, and M. Barlow, "The impact of a hemispheric circulation regime on fall precipitation over North America," Journal of Hydrometeorology, vol. 11, no. 5, pp. 1182-1189, 2010.

[51] J. C. Rogers, "The association between the North Atlantic Oscillation and the Southern Oscillation in the Northern Hemisphere," Monthly Weather Review, vol. 112, no. 10, pp. 1999-2015, 1984. 

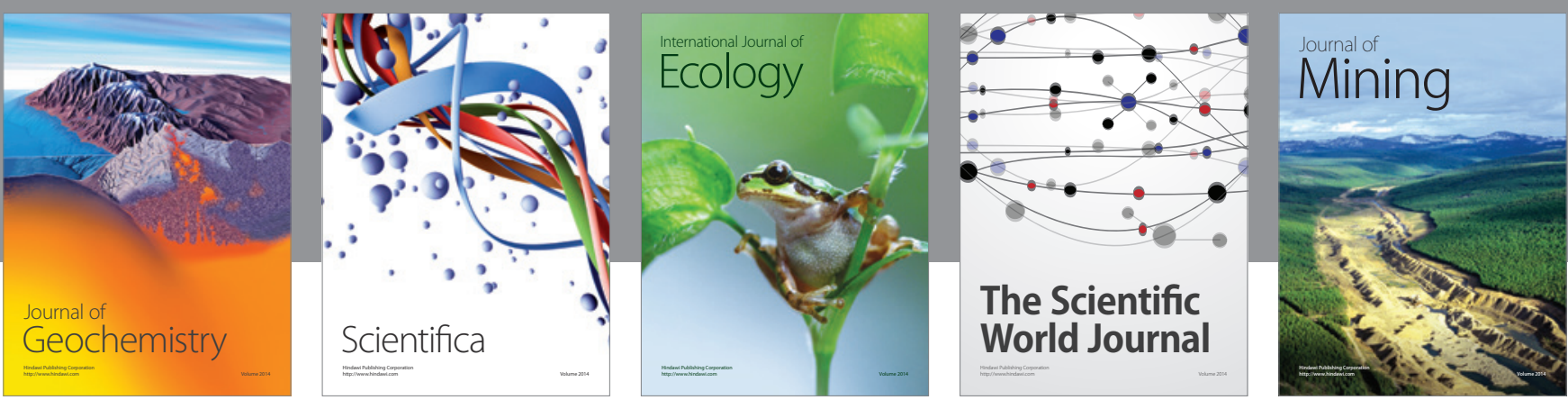

The Scientific World Journal
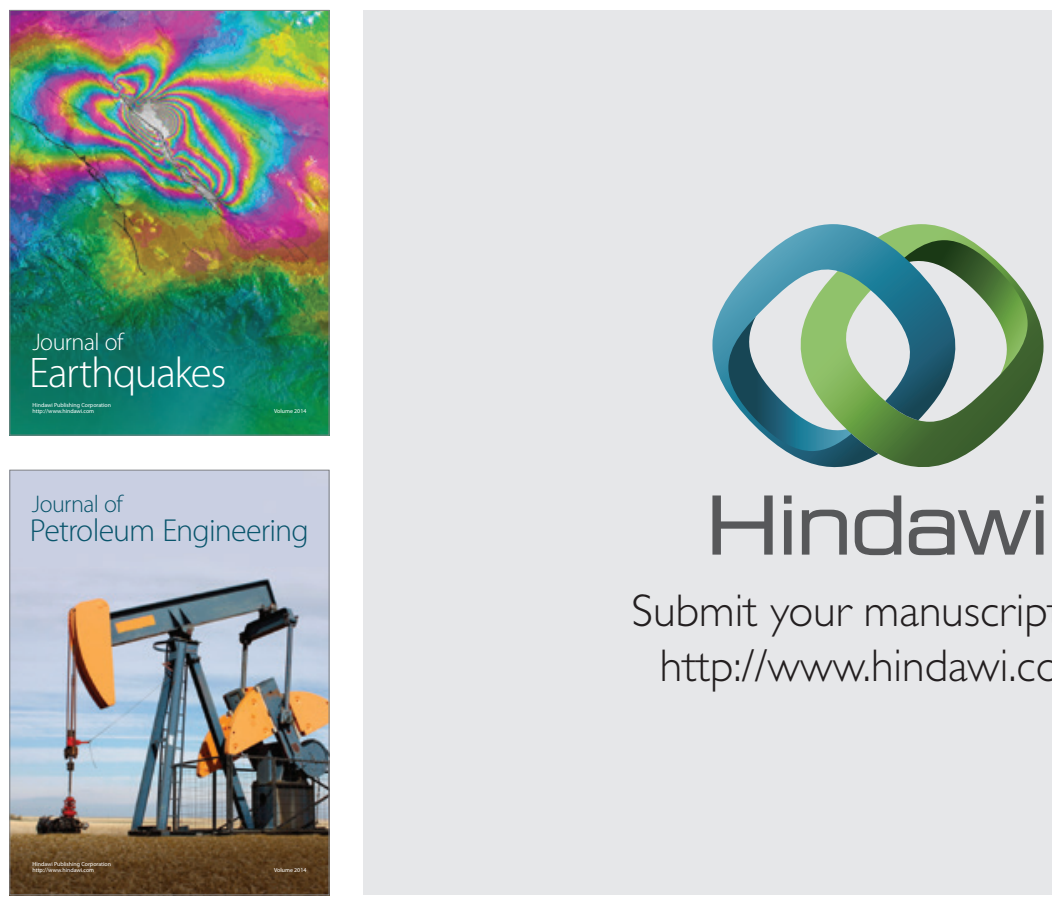

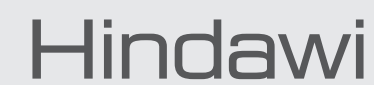

Submit your manuscripts at

http://www.hindawi.com
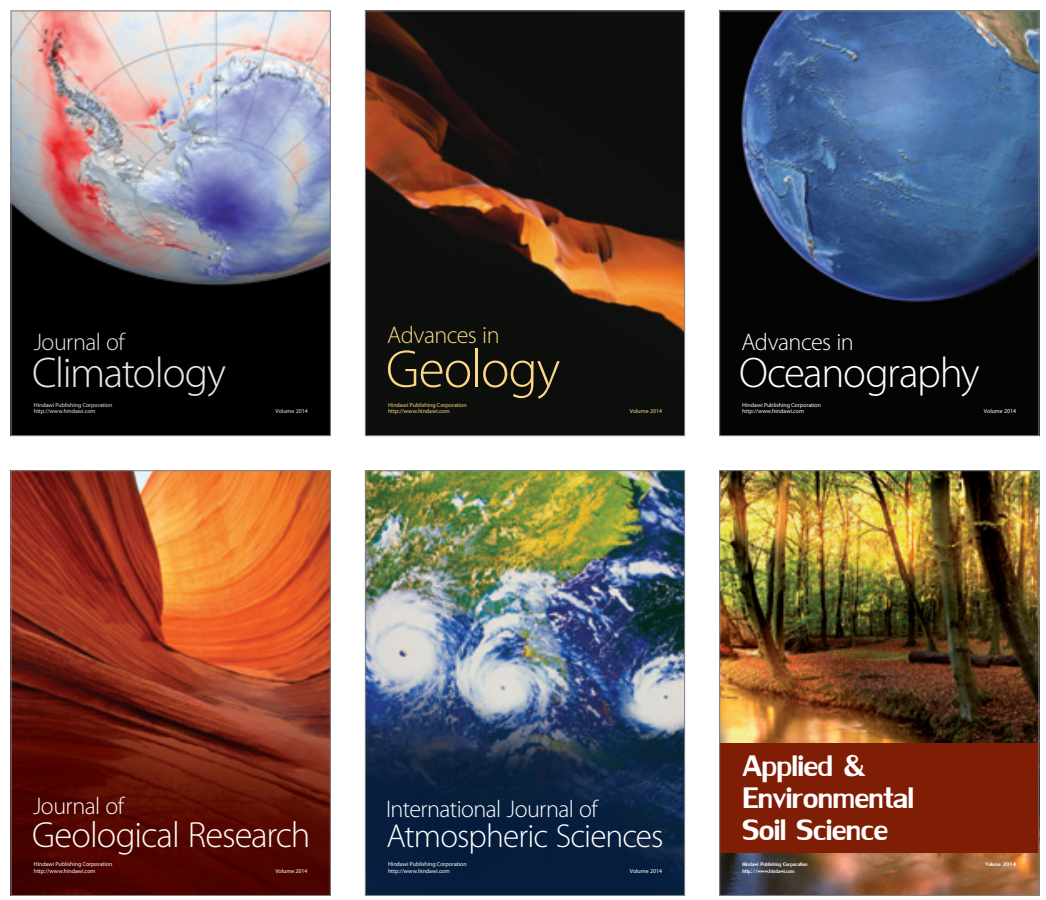
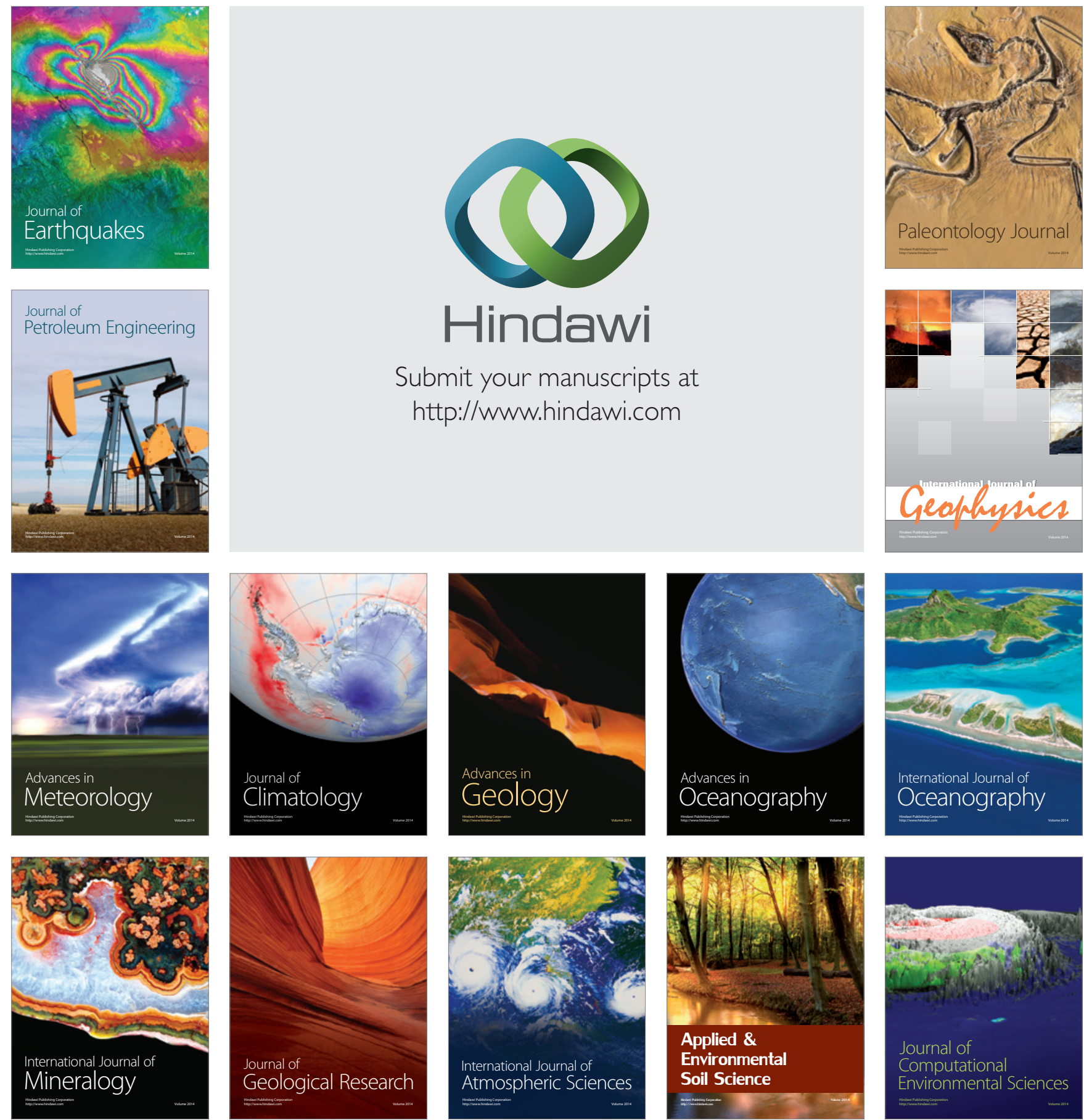